\title{
PUBLICACIONES SOBRE LITERATURA FRANCESA EN ESPAÑA, 1990
}

Alicia Yllera

UNED

\section{Obras colectivas'}

Actes du XF Congrès International de la Société Rencesvals, Barcelona, 1990 (Memorias de la Real Academia de Buenas Letras de Barcelona, XXII).

Anales de Filologia Francesa, 3, 1990, Universidad de Murcia.

Correspondance 1, Ministerio de la Comunidad Francesa de Bélgica, Universidades de Cádiz y Extremadura, 1990.

Cuadernos de Filologia Francesa, 4, 1990, Universidad de Extremadura.

Estudios de Lengua y Literatura Francesa, 4, 1990, Universidad de Cádiz.

Littérature et Double Culture. Literatura y Doble Cultura. Textos recogidos por Geneviève Mouillaud-Fraisse y José María Fernández Cardo, Actas Noesis, Calaceite (Teruel), 1989.

Literatura, lengua y pensamiento de la Revolución Francesa, Actas del Encuentro Internacional sobre el Bicentenario de la Revolución Francesa, ed. Isabel Herrero y Lidia Vázquez, Universidad del País Vasco, 1990.

A partir de este número, por razones de espacio, no se detallan los trabajos aparecidos en obras colectivas publicadas en España y dedicadas integramente a la literatura francesa. 
Margùerite Duras. Actes du Colloque International Valencia 1987, ed. Elena Real, Universidad de Valencia, 1990.

1616. Sociedad española de literatura general y comparada, 6-7, 1988-1989 (1990).

Queste, Etudes de langue et littérature française, 5, 1990, Universidades del País Vasco, Pau, Valencia, Zaragoza.

Investigación franco-española, 2 y 3, 1990, Universidad de Córdoba.

\section{Edad Media}

ARamburu Riera, Francisca, "Constantinople, siège de la troisième fonction dumézilienne dans une chanson de geste française», Etudes Balkaniques, Académie bulgare des sciences, Sofia, 2, 1990, pp. 89-92.

Carmona Fernández, Fernando, «La narrativa lírica medieval: el roman lírico", Ensayos de literatura europea e hispanoamericana, ed. F. Menchacatorre, San Sebastián, Universidad del País Vasco, 1990, pp. 73-82.

LÓPEZ AlCARAZ, Josefa, Los fabliaux (ed. bilingüe), intr., trad. y notas, Murcia, Publicaciones de la Universidad de Murcia, 1990.

Mussons, Ana María, «Berthe ou le labyrinthe généalogique», $R e$ vue des langues romanes, 94, 1990, pp. 39-59.

RIQUER, Isabel DE, Chrétien de Troyes, El Caballero del león, intr. y trad. de --, Madrid, Alianza, 1990 (reimpresión). 
SuÁrez Pascual, M." Pilar, «La Caracterización hiperbólica de los païens en La Chanson de Roland», Investigaciones Semióticas III. Retórica y Lenguajes. Actas del III Simposio Internacional de la Asociación Española de Semiótica, ed. José Romera y Alicia Yllera, Madrid, UNED, II, pp. 417-426.

\section{Siglo XVII}

SERRANo MAÑes, Montserrat, "Le Geôlier de soi-même o Jodelet Prince de Thomas Corneille. Comicidad situacional y lingüística de un personaje», Epos, 6, 1990, pp. 317-330.

Rodriguez Navarro, M. ${ }^{a}$ Victoria, "Algunos aspectos del lenguaje de la confidencia en Jean Racine», Studia Zamorensia, 1990, pp. 309-321.

\section{Siglo XVIII}

BoIXAREU, Mercedes, «La Segunda persona como sujeto “pre-textual" $y$ "post-textual" en la narrativa francesa del siglo XVIII", Investigaciones Semióticas III. Retórica y Lenguajes, II, pp. 209214.

Herrero, Isabel, «L'Ambigüité du point du vue dans Ingénue Saxancour de Rétif de la Bretonne", Etudes Rétiviennes, 13, 1990, pp. 21-40.

Jiménez PlazA, Dolores, «L’Autobiographie sentimentale selon Madame Riccoboni», Trames. Le Roman Sentimental (Actes du Colloque International des 14-15-16 mars 1989), Faculté des Lettres et des Sciences Humaines, Limoges, 1990, pp. 53-67. 
Pérez Pérez, M. Concepción, "Construcción y mecánica del cuerpo libertino en Sade. Experiencia del deseo", Philologia Hispalensis, 4, 1990, pp. 727-738.

PiCAzo GonzÁlez, M. ${ }^{a}$ Dolores, «El Lenguaje del héroe epistolar en Les Liaisons dangereuses de Laclos», Investigaciones Semióticas III. Retórica y Lenguajes, II, pp. 257-266.

Ramirez Gómez, Carmen, «La estructura semiótica de la relación amorosa (en las Mémoires du Comte de Gramont)", Discurso, 5, 1990, pp. 115-126.

VÁzQuez, Lidia, "Censure de la littérature française du XVIII ${ }^{\circ}$ siècle dans l'Espagne éclairée», Littérales, Paris-Nanterre, PU, 1990, spécial «La Bibliothèque en feu».

\section{Siglo XIX}

Arrizabalaga Juan, "Tristan Corbière: Presencia y exilio", Epos, 6, 1990, pp. 437-441.

DIEGo, Rosa DE, «El Preurbanismo progresista: la ciudad utópica de J. Verne en Los Quinientos millones de la Begún», Ephialte, Vitoria, 1990.

LEGUEN, Brigitte, «Descripción del cuerpo femenino en la novela del siglo XIX: Balzac y Stendhal», Investigaciones Semióticas III. Retórica y Lenguajes, II, pp. 29-36.

LÓPEZ Jimenez, Luis, «La Poética de Gautier inspirada por Toledo: una selección de aspectos», Toledo romántico. Simposio. Toledo, Colegio Universitario, 1990.

- "Théophile Gautier ou la Redécouverte du paysage espagnol», Actes du XII Congrès de l'Association Internationale de Littérature Comparée (Munich, 1988), Iudicium, 1990. 
Mariño EsPuelas, Alicia, «Retórica de la ironía: la ironía como signo de destrucción o de encubrimiento de lo fantástico en Claire Lenoir", Investigaciones Semióticas III. Retórica y Lenguajes, II, pp. 115-123.

Palacios Bernal, Concepción, "Lamiel, novela y heroina stendhaliana», Ensayos de literatura europea e hispanoamericana, pp. $367-373$.

Real Ramos, Elena, "Milosz et Valle-Inclan. Echos et discordances», Fins de Siècle: Terme -Evolution- Revolution? Actes du Congrès de la Société Française de Littérature Générale et Comparée, Presses Universitaires, Le Mirail, 1989, pp. 547-556.

Risco Salanova, Cristina, «Noces sanglantes chez Mérimée: $L a$ Venus d'Ille et Lokis», Littératures (Toulouse, Presses Universitaires du Mirail), 22, 1990, pp. 83-91.

ToME, Mario, «Símbolos y mitos del hombre romántico: Les Chimères de Gérard de Nerval», Ensayos de literatura europea e hispanoamericana, pp. 557-563.

URdiales Campos, José Millán, «Inglesas e ingleses en los cuentos de Guy de Maupassant», Barcarola, 34, 1990, pp. 145-155.

\section{Siglo XX}

Altarriba, Antonio, «El Muro en la literatura francesa de las últimas décadas», Literatura (San Sebastián), 10, 1990.

- «La Poesía en el comic», Taka de tinta, 1, segunda época, Barcelona, PPU, 1990.

Ansón ANADón, Antonio, «La Cifra ausente. Retórica de la imagen literaria, collaje y montaje cinematográfico», Investigaciones Semióticas III. Retórica y Lenguajes, I, pp. 155-162. 
BENOIT MORINIĖRE, Claude, "Contemplation et écriture», Marguerite Yourcenar et l'art, l'art de Marguerite Yourcenar, Société Internationale d'Etudes Yourcenariennes, Tours, 1990, pp. 283-293.

- «De l'image du moi à l'image du monde (sur l'oeuvre de Marguerite Yourcenar)", Ensayos de Literatura europea e hispanoamericana, pp. 39-47.

- «La Mort dans les Nouvelles Orientales», Sud. Marguerite Yourcenar, une écriture de la mémoire, hors série 1990, pp. 155165.

- «Les Secrets du regard», Sud, Jean-Marie Le Clézio, n. ${ }^{\circ} 85-86$, 1990, pp. 77-82.

Bermúdez Medina, Dolores, «La inscripción de la pintura en la obra de Remy de Gourmont: Couleurs", Teoria del arte y teoria de la literatura, ed. J. A. Hernández, Cádiz, Seminario de Teoría de la Literatura, Servicio de Publicaciones de la Univ. de Cádiz, 1990, pp. 49-57.

Camero Pérez, Carmen, «La survivance du cadre dans la nouvelle moderne», Littératures 22, pp. 105-112.

- "Amants, heureux amants... de V. Larbaud: un ejemplo de monólogo autónomo", Philologia Hispalensis, 5, 1990, pp. 71-80.

Casado, Loreto, «Un Tout petit cheval: texto y dibujo de Henri Michaux», Literatura y Arte. Ephialte, Vitoria, 1990.

FERNÁndez CARDo, José María, «De la metáfora narrativa a la metáfora filmica", Investigaciones Semióticas III. Retórica y Lenguajes, I, pp. 397-402.

González Salvador, Ana, Prólogo a la ed. de Los Evangelios del diablo de Claude Seignolle, Barcelona, Crítica, 1990.

Goujon, Jean-Paul, Les Chansons de Bilitis de P. Louys, èd. critique, Paris, Gallimard, «Poésie / Gallimard», 1990. 
Goujon, Jean-Paul, Lettres inédites à Georges Louis sur le "Pervigilium Mortis», Dolhain, Compléments, 1990.

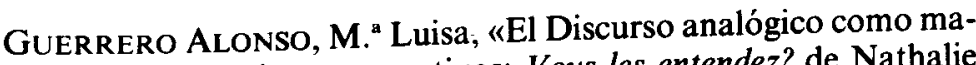
triz de mecanismos narrativos: Vous les entendez? de Nathalie Sarraute», Investigaciones Semióticas III. Retórica y Lenguajes, I, pp. 517-524.

Hermosilla Álvarez, Concepción, «La imagen plástica y el texto poético en Mouvements de Henri Michaux", Teoría del arte y Teoria de la literatura, pp. 155-166.

HeRnÁndez Rodríguez, Francisco Javier, «Montherlant. La corrida comme métaphore», La Tauromachie. Art et littérature, Paris, L'Harmattan, 1990, pp. 77-88.

MuÑoz Romero, María, «Jules Supervielle, le rêveur attentif», Ensayos de Literatura europea e hispanoamericana, pp. 331-337.

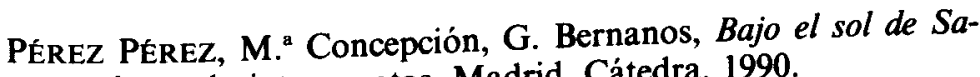
tanás, trad., intr. y notas, Madrid, Cátedra, 1990.

Porras Medrano, Adelaida, «Un ejemplo de percepción diacrónica del espacio: La Colline inspirée de Maurice Barrès», Ensayos de Literatura europea e hispanoamericana, pp. 381-391.

Prado, Javier Del, Para leer a Proust, Madrid, Palas Atenea, 1990.

Real Ramos, Elena, "L'Art de la distance», Marguerite Yourcenar et l'art, l'art de Marguerite Yourcenar, pp. 275-282.

- «Un Espace pour le vide», Sud, Jean-Marie Le Clézio, n. 85 86, 1990, pp. 181-184.

- «Les Grands romans de Marguerite Yourcenar: de Mémoires d'Adrien à Un Homme obscur", Ensayos de Literatura europea e hispanoamericana, pp. 411-421. 
REA'L RAmos, Elena, «Le Voyage dans l'oeuvre narrative de $\mathbf{M}$. Yourcenar», Sud, Marguerite Yourcenar, écriture de la mémoire, hors série, 1990, pp. 197-211.

Ros DEL MORAL, Jesús, «La literatura de entreguerras en Francia: Pierre Mac-Orlan", Ensayos de literatura europea e hispanoamericana, pp. 469-475.

Segarra, Marta, «Du rythme en littérature: Henri Michaux contre l'alexandrin», en J. J. Wunenburger (ed.), Rythme et création, Paris, Ed. de l'Harmattan, 1990.

VÃzQuez, Lidia, «Le Verrou de Fragonard: la instantaneidad visual del libertinage literario», Ephialte, Vitoria, 1990.

\section{Literatura de expresión francesa Literatura francesa fuera de Francia}

Popa-Lisseanu, Doina, "La Palabra extranjera como metáfora», Investigaciones Semióticas III. Retórica y Lenguajes, II, pp. 267274.

- «Les Révolutions d'Istrati», Colloque Panaït Istrati et les Révolutions, Fondation Panaï Istrati avec le concours du Centre National des Lettres, Valence, 1990, pp. 40-47

\section{Literatura comparada}

CAlvet LoRA, Rosa, "Versiones españolas de las obras teatrales de A. Dumas (hijo) (I): La Dame aux camélias (1852-1930)", Epos, 6, 1990, pp. 355-375.

Millán, José Antonio, «En torno al concepto de intertextualidad», Europa en España, España en Europa. Simposium Internacional de Literatura comparada, Universidad de AquisgránUniversidad de Navarra, P.P.U., 1990. 
LÓPEZ Jiménez, Luis, «Don Antonio Machado, lector y crítico de literatura francesa», Antonio Machado, hoy, Actas del Congreso Internacional Antonio Machado, Sevilla, Alfar, 1990.

Ruiz Álvarez, Rafael, Las Comedias de Paul Scarron y sus modelos españoles, Universidad de León, 1990.

Torres Monreal, Francisco, «La loca de Chaillot en España», Jean Giraudoux. Hommages offerts à G. Body, 47, Université de Tours, 1990, pp. 105-108.

YlleRA, Alicia, “"Amigo lector”/“Vulgo tirano": la interacción autor/lector en el prólogo de obras de ficción», Investigaciones Semióticas III. Retórica y Lenguajes, II, pp. 523-533.

10. Historia de las ideas literarias. Crítica literaria

BRuña CuEvas, Manuel, "Sobre la reproducción del discurso", Philologia Hispalensis, 5, 1990, pp. 81-108.

Fernández SÁnChez, Carmen, «El Concepto de ironía: del análisis retórico al literarion, Investigaciones Semióticas III. Retórica y Lenguajes, I, pp. 403-411.

MuÑoz Romero, María, «Operaciones de repérage en el texto literario», Philologia Hispalensis, 5, 1990, pp. 39-50.

Porras MEdrano, Adelaida, «Escritura y objeto arquitectónicon, Teoría del arte y teoría de la literatura, pp. 199-206.

RÁmiRez GOMEZ, C., « ¿La postmodernidad, un nuevo protocolo en el discurso de las artes?", Teoria del arte y teoría de la literatura, pp. 215-220.

SEgARRA, Marta, «El ritmo, un descubrimiento antropológico y poético», Ensayos de literatura europea e hispanoamericana, pp. 529-534.

Yllera, Alicia, «Del Clasicismo francés a la crítica contemporánea. Historia de las ideas literarias (II)», Epos, 6, 1990, pp. 331-353. 